Georgia State University

ScholarWorks @ Georgia State University

7-1-2016

\title{
Enhanced Citizenship Verification and Children's Medicaid Coverage
}

James Marton

Angela Snyder

Mei Zhou

Follow this and additional works at: https://scholarworks.gsu.edu/ghpc_articles

\section{Recommended Citation}

Marton, James; Snyder, Angela; and Zhou, Mei, "Enhanced Citizenship Verification and Children's Medicaid Coverage" (2016). GHPC Articles. 56.

https://scholarworks.gsu.edu/ghpc_articles/56

This Article is brought to you for free and open access by the Georgia Health Policy Center at ScholarWorks @ Georgia State University. It has been accepted for inclusion in GHPC Articles by an authorized administrator of ScholarWorks @ Georgia State University. For more information, please contact scholarworks@gsu.edu. 


\title{
ENHANCED CITIZENSHIP VERIFICATION AND CHILDREN'S MEDICAID COVERAGE
}

\author{
JAMES MARTON, ANGELA SNYDER and MEI ZHOU*
}

\begin{abstract}
This article examines a potential unintended consequence of the mandated Medicaid citizenship verification requirements of the 2005 Deficit Reduction Act (DRA). We investigate whether or not these new rules led to an increase in the Medicaid exit rate among enrollees using state administrative data from Georgia. We do this by comparing the exit rate for children enrolled in Medicaid whose first coverage recertification occurs just after implementation of the DRA (which we refer to as a "high impact" first recertification) with those whose first recertification occurs just prior (which we refer to as a "low impact" first recertification). Our analysis suggests that children in the high-impact first recertification group were about 2 percentage points more likely to exit Medicaid than those in the low-impact group. Furthermore, these additional exits occurred in racial and ethnic groups more likely to be citizens than noncitizens and prereform estimates suggest that there were very few (roughly 0.10\%) noncitizen Medicaid enrollees to begin with. Taken together, our results suggest that the DRAenhanced citizenship verification rules led to an increase in Medicaid disenrollment, and thus a reduction in coverage, among citizens. (JEL I18, I38, J13)
\end{abstract}

\section{INTRODUCTION}

A persistent issue associated with the design of transfer programs in the United States is whether noncitizens are eligible to participate in such programs. Requiring citizenship for program participation introduces the questions of what constitutes sufficient proof of citizenship

*We thank J.S. Butler, Pat Ketsche, Rusty Tchernis, Cynthia Searcy, Aaron Yelowitz, and seminar participants at Georgia State University, the AHEC Conference, and the APPAM Conference for their valuable comments. We thank Subha Basu, Jaesang Sung, and Jamie Turner for their work as research assistants. Any errors are, of course, our own. Finally, we thank the Georgia Department of Community Health for providing us access to the data we use in this article. The opinions and conclusions expressed herein are solely those of the authors and should not be construed as representing the opinions or policy of the Georgia Department of Community Health.

Marton: Associate Professor, Department of Economics, Georgia State University, Andrew Young School of Policy Studies, Atlanta, GA 30302. Phone 404-413-0256, Fax 404-413-0145, E-mail marton@gsu.edu

Snyder: Research Assistant Professor, Georgia Health Policy Center, Georgia State University, Andrew Young School of Policy Studies, Atlanta, GA 30302. Phone 404-4130285, Fax 404-413-0316, E-mail angiesnyder@gsu.edu

Zhou: Senior Research Associate, Georgia Health Policy Center, Georgia State University, Andrew Young School of Policy Studies, Atlanta, GA 30302. Phone 404-4130310, Fax 404-413-0316, E-mail mzhou1@ gsu.edu and whether or not requiring such proof imposes a significant barrier to participation for those eligible. Given this backdrop, a relatively recent federal rule change regarding citizenship verification requirements in state Medicaid programs has received considerable attention in the popular press. ${ }^{1}$ Beginning in July 2006, the Deficit Reduction Act of 2005 (DRA) required most new

1. See for example the following article in the New York Times: http://www.nytimes.com/2006/06/05/washington/ 05medicaid.html?_r=0

\section{ABBREVIATIONS}

ACA: Affordable Care Act

AFDC: Aid to Families with Dependent Children CHIPRA: Children's Health Insurance Program Reauthorization Act

CMS: Centers for Medicare and Medicaid Services

CPS: Current Population Survey

DCH: Department of Community Health

DRA: Deficit Reduction Act

GAO: Government Accountability Office

LIM: Low Income Medicaid

OIG: Office of Inspector General

RSM: Right from the Start Medicaid

SSI: Supplemental Security Income 
Medicaid applicants, as well as most current beneficiaries (at their next recertification of eligibility), to document their citizenship. Acceptable documentation includes a U.S. passport, birth certificate, or driver's license from a state that verifies social security numbers. ${ }^{2}$ The purpose of this article is to investigate the possibility that this rule change led to the unintended consequence of increasing the rate at which citizens exited the Medicaid program using state administrative data on children from Georgia.

Previous research (Bansak and Raphael 2007 and Wolfe and Scrivner 2005) suggests that, in general, increases in the complexity of application and renewal requirements within public insurance programs will lead to reductions in take-up rates and increases in disenrollment rates among those eligible. Thus, if a programmatic priority going forward is to increase the coverage rate of uninsured Medicaid-eligible children, it will be important to have a better understanding of how increases in the requirements to document citizenship impact participation. This topic takes on added significance because of the Affordable Care Act (ACA), as states must verify the citizenship status of individuals obtaining subsidies for coverage through state health insurance exchanges and noncitizens remain ineligible for expanded Medicaid coverage.

One previous study, Sommers (2010), examines the extent to which this rule change increased the ability of Medicaid administrators to ensure that benefits were not going to ineligible noncitizens using data from the Current Population Survey (CPS). The study compares changes in states that already utilized enhanced citizenship verification prior to the reform to changes in those that did not. The results suggest that the DRA reduced Medicaid enrollment among noncitizens, as intended. Because we focus on the potential for an adverse effect on citizens, we view our work as a complement to Sommers (2010).

Medicaid microenrollment data from 2004 to 2008 provided to us by the Georgia Department

2. According to the CMS website, prior to July 2006, individuals were not eligible for Medicaid unless they were either American citizens or qualified aliens; however, beneficiaries could self-declare their citizenship status by checking a box on the application form under penalty of perjury. The DRA required, starting in July 2006, actual documentary evidence of a person's status when applying for Medicaid coverage or, if already enrolled, when recertifying coverage. This must be enforced by states in order to receive their federal Medicaid match. For more on what is considered documentary evidence, see the following link from the CMS website: http://www.cms.gov/Regulations-andGuidance/Legislation/DeficitReductionAct/Citizenship.html of Community Health (DCH) allow us to examine the extent to which the DRA increased the exit rate of enrollees from the program. We compare the exit rate for children enrolled in Medicaid whose first coverage recertification occurs postDRA implementation in the summer and fall of 2005 (which we refer to as a "high impact" first recertification) with those whose first recertification occurs pre-DRA implementation in the winter and spring of 2005 (which we refer to as a "low impact" first recertification). If the DRA caused a greater number of enrollees to lose their coverage, we would expect a higher exit rate for those having a high-impact first recertification as compared to those having a low-impact first recertification, because the main difference between the two groups is shown to be whether or not they were required to produce their original birth certificate in order to recertify their coverage.

Our analysis suggests that children in the high-impact group were about 2 percentage points more likely to exit Medicaid than those in the low-impact group. Such a large difference is not observed if we compare Medicaid children whose first recertification occurred in the summer or fall of 2004 with those whose first recertification occurred in the winter or spring of 2004. This gives us confidence that our results are not simply reflecting seasonal differences in exit rates. In addition, we do not observe an impact of the DRA among children enrolled in Medicaid via the Supplemental Security Income (SSI) program, as those children were already subject to enhanced citizenship verification. Furthermore, these additional exits occurred in racial and ethnic groups more likely to be citizens than noncitizens, and prereform estimates suggest that there were very few (roughly $0.10 \%$ ) noncitizen Medicaid enrollees to begin with (U.S. Government Accountability Office 2007). Taken together, our results suggest that the DRA-enhanced citizenship verification rules led to an increase in Medicaid disenrollment, and thus a reduction in coverage, among citizens.

\section{LITERATURE REVIEW}

States face competing priorities when implementing public health insurance programs. One such challenge is balancing the accuracy of eligibility determination with the ease of Medicaid enrollment and retention for eligible individuals. ${ }^{3}$

3. See Klevin and Kopczuk (2011) for a recent theoretical analysis of this issue. 
This is especially true given DRA-enhanced citizenship verification requirements and the incentives given to states for administrative simplification and increased enrollment under the Children's Health Insurance Program Reauthorization Act (CHIPRA) of 2009. In addition, under the ACA, states must balance the eligibility policies and system linkages required between the health insurance exchanges and Medicaid with the shrinking pool of federal uncompensated care dollars in order to minimize use of state funds and assure individuals are enrolled in the appropriate programs.

Prior to DRA enactment, the Office of the Inspector General recognized this challenge and reported on citizenship self-declaration policies within Medicaid (U.S. Department of Health and Human Services 2005). In a descriptive study of state Medicaid directors, the Office of Inspector General (OIG) found that most states allowing self-declaration of citizenship reported they had not seen a problem with noncitizens gaining Medicaid coverage as evidenced by their post eligibility quality control activities. Only one state, Oregon, quantified the problem, estimating that about $1 \%$ of their mailed-in Medicaid applications (U.S. Department of Health and Human Services 2005) had citizenship-related problems. Medicaid directors also indicated that if all Medicaid applicants were required to provide documentary evidence of U.S. citizenship, then this would delay eligibility determinations, increase eligibility personnel costs, as well as be burdensome for applicants and current enrollees (U.S. Department of Health and Human Services 2005).

The peer-reviewed literature supports the notion that decreasing the administrative burden for applicants leads to increases in take-up and retention of public coverage. Studies of state policies suggest that eliminating asset tests, allowing for presumptive eligibility, offering continuous coverage, simplifying applications, reducing waiting periods, and increasing outreach activities all have a positive impact on take-up and retention (Bansak and Raphael 2007; Bronchetti 2014; Wolfe and Scrivner 2005). Furthermore, transitions between Medicaid and separate CHIP programs (Ketsche et al. 2007a, 2007b), changes from passive to an active renewal process (Herndon et al. 2008), welfare reform (Watson 2014), managed care implementation (Marton and Yelowitz 2015; Marton, Yelowitz, and Talbert 2014), as well as premium increases (Dague 2014; Kenney et al. 2006; Kenney et al. 2007,
Marton 2007, Marton, Ketsche, and Zhou, 2010; Marton and Talbert 2010; Marton et al. 2015) lead to increases in disenrollment and increased gaps in coverage, otherwise known as churning.

Thus, this prior research suggests that the implementation of increased citizenship documentation requirements should negatively impact both take-up and retention of citizens. This is consistent with the self-reported survey research done by the Government Accounting Office of 44 states post-DRA implementation (U.S. Government Accountability Office 2007). The Government Accountability Office (GAO) reported that citizenship documentation requirements resulted in enrollment declines for eligible citizens and posed administration burdens on states. Of those surveyed, 22 of the 44 states reported a decline in enrollment, 12 reported no change, and 10 stated that they did not know the effect of the requirement. In its response to the $\mathrm{GAO}$, the Centers for Medicare and Medicaid Services (CMS) questioned the validity of the results saying they were all based on anecdotal statements without supporting data analysis to attribute all declines to the new requirements. ${ }^{4}$

A Commonwealth Fund Report identified enrollment declines by a closer examination of data from seven states during the 6 months that followed implementation of the enhanced citizenship verification rules compared to the 6 months that preceded the change (Summer 2009). This study found that the new citizenship documentation requirements made the enrollment and renewal process more complex, administratively burdensome, and costly. Summer (2009) also found the impact on applicants and beneficiaries differed by state depending, in part, on the state's infrastructure and approach to implementation. Several states reported that while the policy is aimed at undocumented immigrants, predominantly Hispanics in the United States, it was more likely to negatively impact other population groups who are citizens and are eligible for and/or participating in public programs (Ross 2007; Summer 2009). Angus and DeVoe (2010) looked specifically at Oregon's Family Planning Program implemented through a Medicaid waiver. They found an association between enhanced Medicaid citizenship documentation

4. The CMS is part of the U.S. Department of Health and Human Services (HHS) and is responsible for administering Medicare, Medicaid, the Children's Health Insurance Program (CHIP), and parts of the Affordable Care Act (ACA). For further information, please see the CMS website: https:// www.cms.gov/ 
FIGURE 1

Different Types of First Recertifications

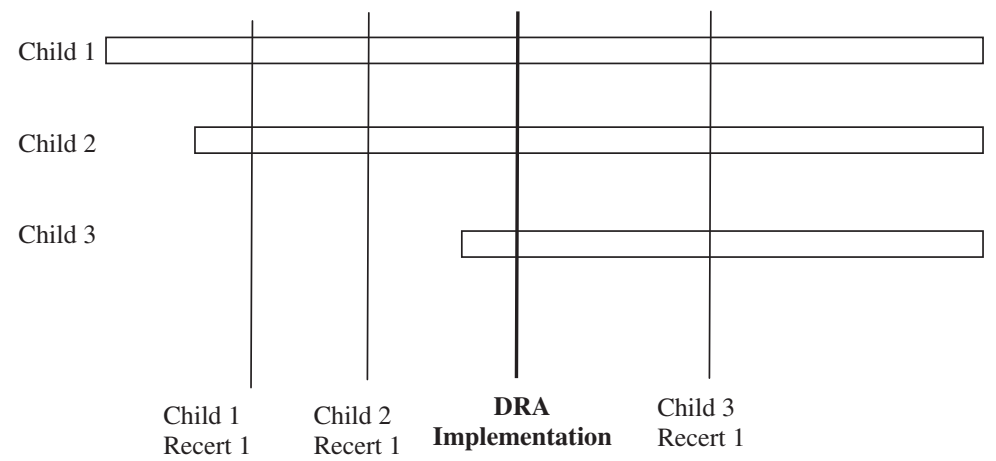

requirements and reductions in access to family planning for young adults as well as an increasing strain on the social safety net.

Sommers (2010) uses the CPS to estimate a difference-in-differences model to compare states classified by the author as not having major changes in Medicaid citizenship verification policy with all other states before and after the implementation of the DRA. The primary outcome of interest is the Medicaid coverage status of noncitizens and he finds that one in four adult noncitizens in Medicaid and one in eight child noncitizens were screened out by the DRA annually.

To summarize, these previous studies and reports suggest that there were likely not a large number of noncitizens obtaining Medicaid coverage prior to the DRA. For its own DRA cost analysis, CMS itself assumed that in fiscal year 2008 50,000 noncitizen beneficiaries would be determined to be ineligible as a result of the DRA (U.S. Government Accountability Office 2007). This represents roughly $0.10 \%$ of the average Medicaid enrollment of 49.1 million people around this time (Truffer et al. 2008). While Sommers (2010) shows that the DRA was successful in reducing the small number of noncitizens participating in Medicaid, left unanswered is an empirical estimate of the associated cost in terms of disruptions in the Medicaid coverage of citizens. Many of these studies and reports suggest anecdotally that this cost may not be trivial.

\section{IDENTIFICATION STRATEGY}

Our basic identification strategy is to restrict attention to children that initiated Medicaid coverage in the year prior to the reform and compare the recertification experience of ones that start earlier in the year to those that started later in the year. This is because those that started earlier in the year would not be subject to enhanced citizenship verification upon their first 6-month eligibility recertification whereas those that started later in the year would. We refer to those experiencing their first recertification on or after January 2006 as having a high-impact first recertification (coverage spell started in the summer or fall of 2005) and others as having a low-impact first recertification (coverage spell started in the winter or spring of 2005).

Figure 1 gives an illustration of two children with a low-impact first recertification and one child with a high-impact first recertification. Child 1 and child 2 enrolled prior to the DRA and also had their first recertification prior to the reform. Child 3 also enrolled prior to the DRA, but faces the stricter requirements at their first recertification. If there is an impact of this rule change on enrolled children, such highimpact first recertifications would be the most likely place for it to appear. In order to assess the magnitude of this effect, we can compare the exit rate during these high-impact first recertifications with the low-impact first recertifications that occurred in months just before the reform. Because all of these children started their spell in the year prior to the reform in the same eligibility category, they are arguably otherwise similar.

In order to test our identification strategy, we perform two placebo tests. First, we perform the same analysis on children whose coverage spells start in 2004. The DRA could not have caused children starting their Medicaid coverage in the 
FIGURE 2

Monthly Enrollment of Children in Georgia Medicaid (July 2003-June 2008)

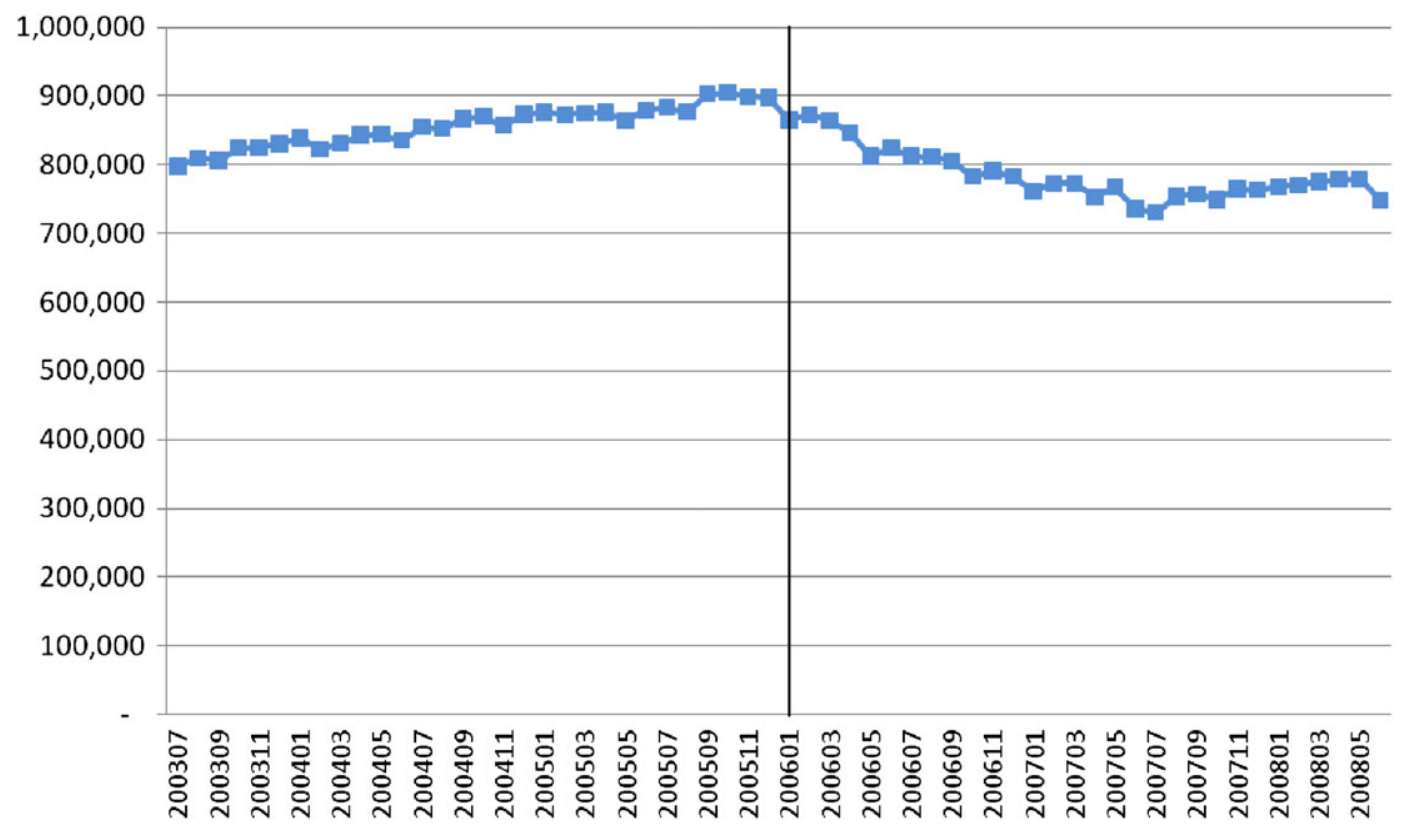

summer or fall of 2004 (the placebo high-impact group) to exit coverage at a higher rate than those that started in the winter or spring of 2004 (the placebo low-impact group). This placebo test allows us to determine the extent to which any differences in the exit rates we observe among our 2005 Medicaid coverage spells is being driven by seasonality, rather than the DRA. As a second placebo test, we perform the same analysis on children jointly enrolled in Georgia Medicaid and the federal SSI program during 2005. Because these children are enrolled in the SSI program, they were already subject to enhanced citizenship verification. Thus, we should not expect to see any impact of the DRA on these children and they will not be included in our main 2005 analysis sample described in detail below.

\section{DATA}

In order to implement the identification strategy described in the last section, we would need data on Medicaid enrollment spells that are not typically publically available, including the start month of an enrollee's spell of Medicaid coverage, the end month for that spell, as well as the eligibility category associated with the spell.
The Georgia DCH provided us with the universe of confidential Georgia Medicaid administrative enrollment records for each month between July 2003 and June 2008 because they were interested in the impact the DRA-enhanced citizenship verification requirements were having in their state.

To give a sense of the scope of Medicaid coverage for children in Georgia, Figure 2 graphs the total monthly enrollment of children in Georgia Medicaid during this time. Georgia implemented the enhanced Medicaid citizenship verification rules prescribed by the DRA in January 2006. The number of children in Medicaid rises above 900,000 per month in the months just prior to the policy change and then falls to about 750,000 in June 2008. This graph does not account for contemporaneous confounders, such as changes in economic conditions. In addition, an aggregate enrollment count such as this may hide different patterns for different types of children.

In order to identify the impact of the DRA, we restrict attention to children enrolled through the eligibility category for which the reform was most likely to be binding, the "Low Income Medicaid" or "LIM" eligibility category (which is based on the 1996 Aid to Families with Dependent Children [AFDC] income 
TABLE 1

Descriptive Statistics for Georgia LIM Medicaid Spells (Initiated between December 2004 and December 2005)

\begin{tabular}{lccc}
\hline \# spells & $\begin{array}{c}\text { All Cohorts } \\
\mathbf{1 0 4 , 0 8 1}\end{array}$ & $\begin{array}{c}\text { Low Impact } \\
\mathbf{4 0 , 5 7 2}\end{array}$ & $\begin{array}{c}\text { High Impact } \\
\mathbf{6 3 , 5 0 9}\end{array}$ \\
\hline Demographics & & & \\
$\quad$ Age under 1*** & $17.82 \%$ & $18.72 \%$ & $17.25 \%$ \\
Age 1-5 & $31.36 \%$ & $31.53 \%$ & $31.25 \%$ \\
Age 6-12*** & $27.80 \%$ & $27.21 \%$ & $28.18 \%$ \\
Age 13-18*** & $23.02 \%$ & $22.54 \%$ & $23.33 \%$ \\
Female & $51.08 \%$ & $51.10 \%$ & $51.06 \%$ \\
Non-white*** & $65.30 \%$ & $64.14 \%$ & $66.03 \%$ \\
Atlanta metro*** & $39.13 \%$ & $38.10 \%$ & $39.79 \%$ \\
Spell characteristics & & & 17.63 \\
Average spell length (months)*** & 18.46 & 19.75 & $79.05 \%$ \\
Spells ending in an observed exit*** & $80.50 \%$ & $82.78 \%$ & $20.95 \%$ \\
Spells that are right-censored*** & $19.50 \%$ & $17.22 \%$ & \\
\hline
\end{tabular}

*** Difference statistically significant at the $1 \%$ level.

standards). ${ }^{5}$ We further restrict our attention to the 104,081 Georgia LIM Medicaid spells for children initiated between December 2004 and December 2005. Children initiating these spells did not have to meet the enhanced citizenship verification requirement in order to enroll. In addition, children starting their spell between December 2004 and April 2005 experienced their first recertification prior to DRA implementation in Georgia (i.e., the low-impact first recertification group), while children starting their spell between May 2005 and December 2006 experienced their first recertification AFTER DRA implementation (i.e., the high-impact first recertification group) ${ }^{6}$

5. Most of the children in Georgia Medicaid are typically eligible for coverage through one of three eligibility categories: Low Income Medicaid (LIM), Right from the Start Medicaid (RSM) - Georgia's low-income expansion population eligibility category that also covers pregnancy-related Medicaid eligibility - and those with a disability who receive Supplemental Security Income (SSI). We restrict our study cohort to LIM enrollments because all LIM beneficiaries recertifying their Medicaid coverage would be newly required to provide proof of citizenship after the implementation of the DRA. As mentioned, disabled children eligible for Medicaid through their joint enrollment in the SSI program have always been required to provide proof of citizenship due to the federal nature of the SSI program. Because RSM includes many newborns that are born into Medicaid coverage and thus would not need to provide proof of citizenship, they are excluded from our analysis.

6. It should be noted here that we dropped spells starting in September 2005 from our sample because of an administrative data issue. Both the number of new spells initiated in that month and the subsequent number of exits generated by those spells are roughly twice as high as in any other month in the data we were provided. One possible explanation is that there may have been some sort of double counting going on in terms of spell initiation, so the increased number of exits is one way to address that from a programmatic head counting perspective.
Table 1 presents descriptive statistics for the LIM spells that are the focus of our analysis. The descriptive statistics are given for all spells as well as separated by those that faced lowversus high-impact first recertifications. Overall, the average spell length is 18 months and $81 \%$ of the coverage spells end before June 2008. Spells that are ongoing or initiated in June 2008 are treated as right-censored. Spells associated with a low-impact first recertification appear to be slightly more likely to end in an exit as compared to spells associated with a high-impact first recertification. This may seem somewhat surprising, but it is important to remember that the reform does not impact all enrolled children at the same time. This motivates our approach of focusing on months in which we are most likely to see an impact of the reform and compare them to otherwise similar months.

Significance tests suggest that most of the demographic differences between the two groups are statistically significant, but we view the absolute size of these differences to be small in terms of economic significance. Our high-impact group of 63,509 enrollees represents 1,119,901 enrollee-months of data and our low-impact group of 40,572 enrollees represents 801,376 enrollee-months of data, so our total sample size for these significance tests is 1,921,277 enrolleemonths, which suggests that we have a great deal of precision to identify even small differences between the two groups. Given that we are not dealing with random assignment between the two groups, we will control for the observable characteristics given in Table 1 in our hazard regression analysis. 


\section{EMPIRICAL SPECIFICATION}

We use a hazard model approach to estimate the impact of the reform on the duration of each LIM child's enrollment in Medicaid using the 104,081 spells described in Table 1. Of these spells, 83,789 end in an exit prior to the last month in our data, June 2008. As is common in the literature, if the child remains enrolled in June 2008 or ages out of the program upon turning 19 , we treat their spell as right-censored. State Medicaid administrative enrollment data does not typically identify the reason for a child's exit from coverage and that is also true in Georgia. ${ }^{7}$

The hazard model we estimate is specified in Equation (1) below:

$$
\text { (1) } H(t)=\exp \left(X_{1 t} / \beta_{1}\right) * \exp \left(t \alpha_{1}+t^{2} \alpha_{2}\right) \text {. }
$$

Here, we are estimating the impact of the observable characteristics parametrically using the standard proportional hazards functional form $\left(\exp \left(X_{1 t}{ }^{\prime} \beta_{1}\right)\right)$. Included in the vector $X_{1 t}$ are dummies for high-impact first recertification months, low-impact first recertification months, and other recertification months. ${ }^{8}$

We also include in this vector the demographic controls described in Table 1 and an indicator for any months with a higher than average unemployment rate. A key component of any analysis of time varying covariates is the proper specification of the baseline hazard. Rather than modeling the baseline hazard in the standard way (using the

7. This implies there is no code in the data for a termination of a child's coverage due to the inability to produce the child's original birth certificate. This also implies we cannot directly differentiate between a child that loses Medicaid coverage because of the DRA, one that drops Medicaid coverage as a result of gaining private insurance coverage, and one that drops Medicaid coverage in Georgia after moving to another state.

8. As described, the purpose of focusing on comparing the first recertification between the "high" and "low" impact groups is to make a clean comparison. Both groups start their enrollment spells under the pre-DRA citizenship rules. The only difference is that the high-impact group has to show their original birth certificate upon their first recertification while the low-impact group does not. The subsequent recertifications for the high-impact group are classified as "other" because the child would not have them if the child's family were not able to produce their birth certificate at their first (high impact) recertification. The subsequent recertifications for the low-impact group are a mix of one eventual high-impact recertification and then additional recertifications if the child's family was able to produce their birth certificate. We do not focus on that eventual high-impact recertification because it happens further away from the start of the child's spell (if the child remains enrolled long enough), as they would have already successfully recertified their coverage at least one time before the start of the DRA citizenship rules.
Weibull distribution), we include a quadratic in time on the right-hand side of our model $\left(\exp \left(t \alpha_{j 1}\right.\right.$ $\left.+t^{2} \alpha_{j 2}\right)$ ) to control for any general temporal patterns in program exits. While our approach to modeling the baseline hazard is still ultimately a parametric one, it does provide more flexibility than the Weibull distribution, because our approach allows for the estimation of two parameters rather than the single Weibull shape parameter. ${ }^{9}$ We will test the sensitivity of our results to this assumption below.

\section{RESULTS}

In this section, we first present descriptive graphical evidence regarding the impact of the DRA on children's disenrollment from Medicaid in Georgia. Next, we describe the results of our primary empirical hazard model specification and the two placebo tests previously mentioned. We then present the results of a simulation exercise based on our primary results. Finally, we discuss several additional specification checks.

\section{A. The Impact of the DRA on Enrollment Duration for Enrolled Children: Descriptive Evidence}

Figure 3A plots the unadjusted survival curve for the LIM Medicaid children described in Table 1 experiencing a high-impact first recertification (those that started coverage in the summer or fall of 2005) in black and the survival curve for children experiencing a low-impact first recertification (those that started coverage in the winter or spring of 2005) in gray. The $x$ axis represents months since the start of a spell, which is sometimes referred to as "spell time" as opposed to "calendar time." The $y$ axis represents the proportion of children initially enrolled in each group that remain enrolled. We would expect the survival curves to look similar for the "high impact" and "low impact" groups prior to their first recertification, which occurs around month 6 . At that point, we would expect the survival curve for those in the high-impact group to dip below the survival curve for the low-impact group because children in the high-impact group had to provide their original birth certificate at their eligibility recertification while children in the low-impact group did not. This is indeed what we observe in

9. Marton, Ketsche, and Zhou (2010) use a similar approach to estimate the impact of premium changes on the duration of enrollment in public coverage. 
FIGURE 3

Exit Patterns: (A) 2005 Main LIM Sample and (B) 2004 Placebo LIM Sample

A

Exit Patterns (Dec 2004-Dec 2005)

First 12 Months

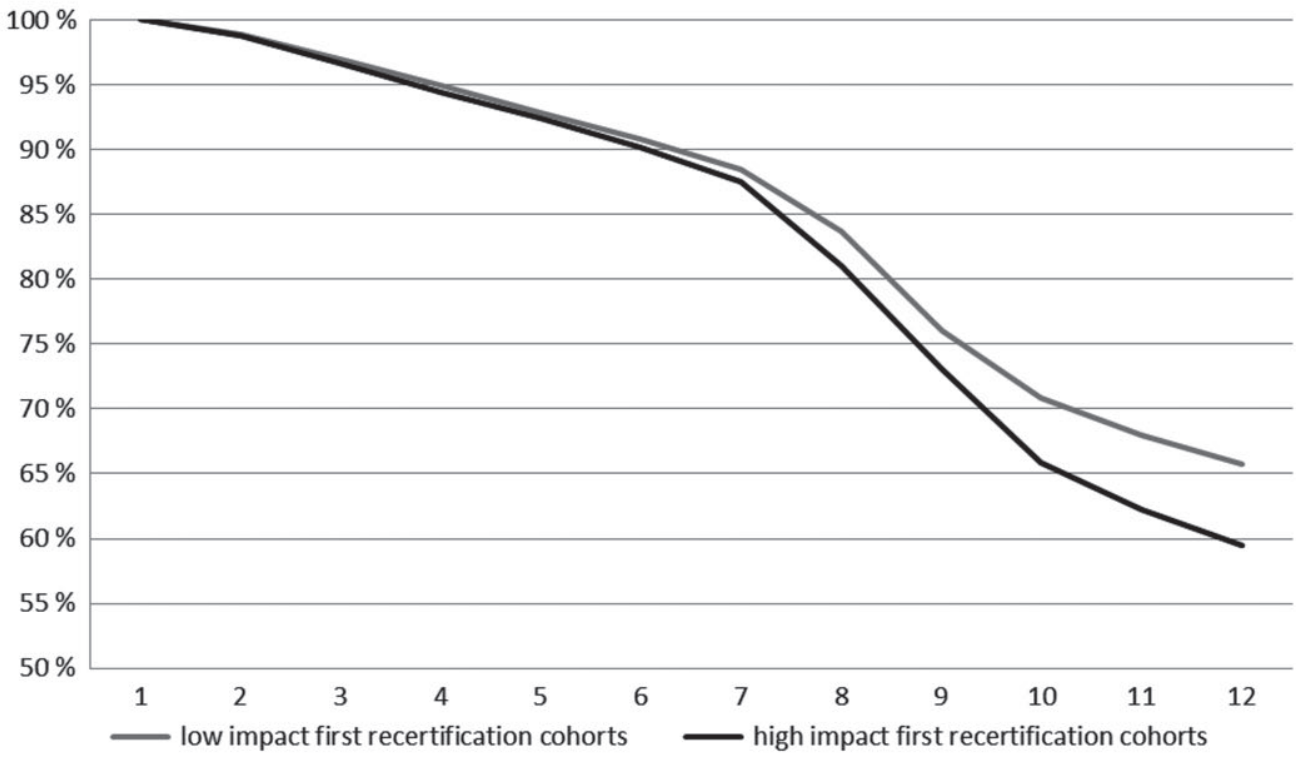

B

Placebo Test - Exit Patterns 1 Year Prior to

Reform (Dec 2003-Dec 2004)

First 12 Months

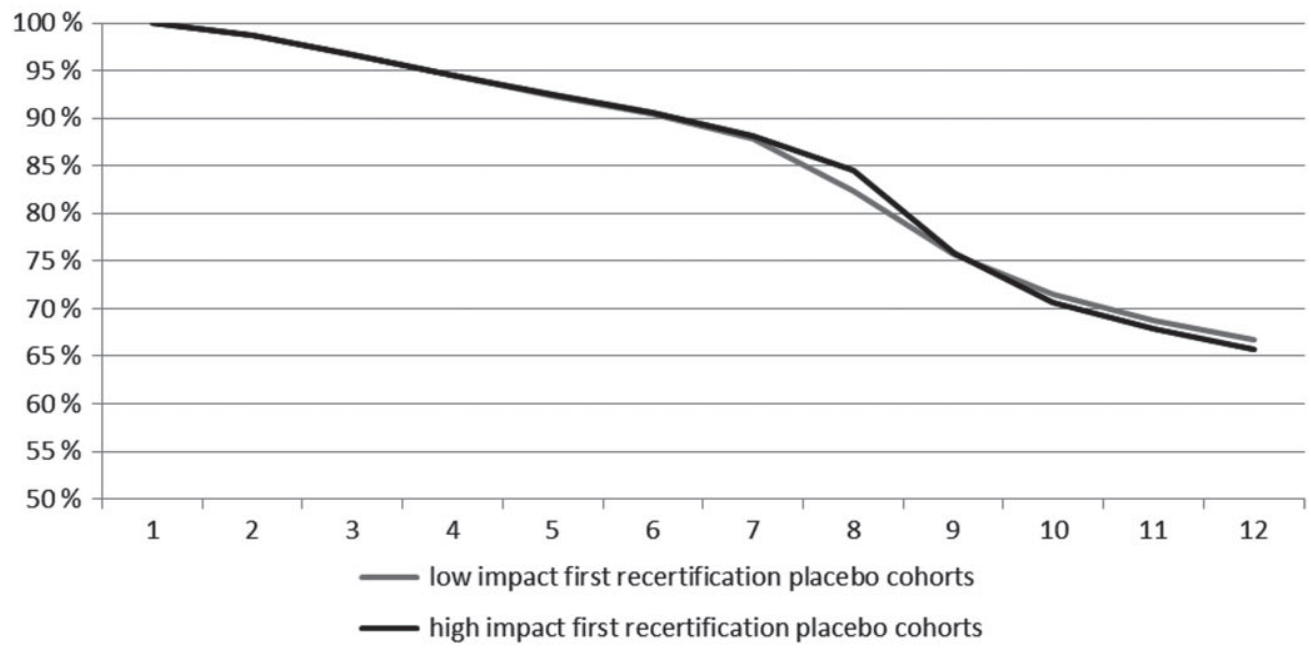

the graph, although with this graph alone, we cannot rule out that this reflects some sort of seasonal difference in disenrollment patterns.

As an informal placebo test and check on disenrollment patterns, Figure 3B plots the same types of unadjusted survival curves for children enrolled in 2004, 2 years prior to DRA implementation. The placebo high-impact group starts their coverage in the summer or fall of 2004 and the placebo low-impact group starts their coverage in the winter or spring of 2004. Absent any seasonal differences, we would expect 
TABLE 2

Duration Model for Georgia LIM Medicaid Spells for Children (Initiated between December 2004 and December 2005)

\begin{tabular}{|c|c|c|c|c|}
\hline Variable & Hazard & Standard Error & $p$ Value & Absolute Effect \\
\hline High-impact first recertification & 2.62 & 0.026 & 0.00 & $11.41 \%$ \\
\hline Female & 1.02 & 0.007 & 0.01 & $4.44 \%$ \\
\hline Non-white & 0.93 & 0.008 & 0.00 & $4.06 \%$ \\
\hline Age under 1 & 0.48 & 0.005 & 0.00 & $2.08 \%$ \\
\hline Age $1-5$ & 0.77 & 0.007 & 0.00 & $3.38 \%$ \\
\hline Age $6-12$ & 0.78 & 0.007 & 0.00 & $3.41 \%$ \\
\hline High unemployment month & 0.90 & 0.008 & 0.00 & $3.91 \%$ \\
\hline Time & 1.12 & 0.002 & 0.00 & $4.88 \%$ \\
\hline Time squared & 1.00 & 0.000 & 0.00 & $4.35 \%$ \\
\hline Low-impact first recertification & 2.18 & 0.029 & 0.00 & $9.52 \%$ \\
\hline Other recertification & 1.23 & 0.012 & 0.00 & $5.36 \%$ \\
\hline \# spells & 104,081 & & & \\
\hline \# exits & 83,789 & & & \\
\hline Log-likelihood & -130719.02 & & & \\
\hline Average spell length & 18.5 & & & \\
\hline Average exit probability & $4.36 \%$ & & & \\
\hline $\begin{array}{l}\text { Test statistic for test of equality of high-impact and } \\
\text { low-impact hazards }\end{array}$ & 152.06 & & & \\
\hline$p$ value & 0.0000 & & & \\
\hline
\end{tabular}

the two survival curves to look similar since both groups faced pre-DRA first recertification procedures. The results are as expected. Thus, this pair of graphs provides some suggestive evidence that the DRA led to an increase in Medicaid exits among children and that this increase may not be explained by seasonal differences in exit patterns. We next investigate this more formally in a multivariate hazard regression context.

\section{B. The Impact of the DRA on Enrollment} Duration for Enrolled Children: Regression Results

Table 2 provides estimation results for Equation (1) using the 104,081 LIM children Medicaid enrollment spells described in Table 1. The key coefficient of interest is on the highimpact first recertification indicator, because these are the months in which the enhanced citizenship verification was first binding for children starting coverage in the summer or fall of 2005. The estimated hazard coefficient associated with the high-impact first recertification indicator is 2.62 and highly statistically significant. This suggests that children enrolled in a high-impact first recertification month are $162 \%$ more likely to exit relative to other months. When compared to the average monthly exit probability in the sample of $4.36 \%$, this coefficient represents a monthly exit probability of $11.41 \%$. We call this the "absolute effect" associated with a high-impact first recertification.

We can compare this exit rate to that of the first (low-impact) rectification for children who were enrolled just prior to the reform (starting coverage in the winter or spring of 2005) and as a result were not exposed to enhanced citizenship verification during their first recertification. The estimated hazard coefficient for a low-impact first recertification is 2.18 and also highly statistically significant. This implies that the monthly exit rate associated with a lowimpact first recertification is $9.52 \%$, which is lower than the $11.41 \%$ monthly exit rate associated with a high-impact first recertification. Table 2 also reports that the test statistic associated with a test of the equality of these two coefficients is 152.06 , so the difference between the high- and low-impact first recertification hazards is highly statistically significant.

Both coefficients might seem like big differences relative to the baseline, but it is important to remember that exit rates during recertification months are always higher than during nonrecertification months. For this reason, we also include controls for all other recertifications in the model (estimated hazard coefficient 1.23, absolute effect $5.36 \%$ ). Table 2 also suggests that male and nonwhite children are overall less likely to exit as are children aged 12 and under, when compared to children aged 13-18. The linear and quadratic 
TABLE 3

Duration Model for Georgia Medicaid Spells for Children: 2005 Main LIM Sample versus 2004 Placebo LIM Sample and 2005 Placebo SSI Sample (Initiated between December 2004 and December 2005)

\begin{tabular}{|c|c|c|c|}
\hline & 2005 Main LIM & 2004 Placebo LIM & 2005 Placebo SSI \\
\hline high_impact_first_recert & $2.62 * * *$ & $2.44 * * *$ & 0.88 \\
\hline abs. effect & $11.41 \%$ & $9.55 \%$ & $1.54 \%$ \\
\hline low_impact_first_recert & $2.18 * * *$ & $2.30 * * *$ & 1.05 \\
\hline abs. effect & $9.52 \%$ & $9.00 \%$ & $1.84 \%$ \\
\hline other_recerts & $1.23 * * *$ & $1.23 * * *$ & $0.83 * * *$ \\
\hline abs. effect & $5.36 \%$ & $4.83 \%$ & $1.46 \%$ \\
\hline \# spells & 104,081 & 118,974 & 3,211 \\
\hline \# exits & 83,789 & 101,766 & 1,508 \\
\hline Log-likelihood & $-130,719.02$ & $-157,130.06$ & $-3,380$ \\
\hline Average spell length & 18.46 & 21.83 & 26.83 \\
\hline Average exit probability & $4.36 \%$ & $3.92 \%$ & $1.75 \%$ \\
\hline $\begin{array}{l}\text { Test statistic for test of equality of high-impact and } \\
\text { low-impact hazards }\end{array}$ & 152.06 & 17.66 & 1.24 \\
\hline$p$ value & 0.0000 & 0.000 & 0.2655 \\
\hline
\end{tabular}

***Difference statistically significant at the $1 \%$ level.

time trend terms that model the baseline hazard suggest that children are more likely to exit over time. ${ }^{10}$

\section{Placebo Tests}

Figure 3B described above motivates our first formal placebo test in which we replicate our 2005 LIM child hazard analysis on 2004 LIM children. The 6-month exit patterns of children newly enrolled in Medicaid via LIM in 2004 should not be influenced by the DRA. Table 3 restates our primary results based on our 2005 LIM sample in column 1 and states the results of our 2004 LIM placebo hazard model in column 2. A comparison suggests a larger difference between the high- and low-impact groups in our 2005 LIM sample than in our 2004 LIM

10. An alternative to including the recertification dummies would be to instead include a post-DRA-enhanced citizenship verification dummy on the right hand side of the model. We expect that such an approach would be a noisy indicator of the impact of the reform because it simply compares each child's experience in the prereform period versus the postreform period. As discussed above, a child that enrolls just prior to the reform, say December 2005, would not have to provide enhanced citizenship on January 1, 2006. Instead, this would be required at their 6-month recertification in May 2006. If the child provides the proper documentation and meets any other eligibility requirements, then their coverage will continue and additional citizenship documentation will not be required during future recertifications. If they cannot, then they will be disenrolled. A simple postperiod dummy would treat May 2006 the same as any other postreform month. Thus, this example suggests that a postperiod dummy would not be the best way to isolate the impact of the reform. placebo sample, as expected. One interpretation of the small, but statistically significant difference between the 2004 placebo high-impact hazard estimate and the 2004 placebo low-impact hazard is that it represents an estimate of the effect of seasonality on exit rates. We quantify the size of the seasonality effect and compare it to our estimate of the effect of the DRA in a set of simulations described in the next subsection.

Our second placebo test takes advantage of the fact that children enrolled in Medicaid via the SSI program were already subject to enhanced citizenship verification due to the federal nature of the SSI program. The 6-month exit patterns of children newly enrolled in Medicaid via SSI in 2005 should not be influenced by the DRA. The third column of Table 3 reports the results of our 2005 SSI placebo hazard model. The high- and low-impact first recertification hazard estimates, as well as the difference between them, are not statistically significant, which support the notion that SSI children were not impacted by the DRA.

The fact that the results of both of these placebo tests are as expected gives us confidence that our main 2005 LIM sample is the appropriate one to measure the impact of the DRA. Given that SSI children are generally less likely to exit Medicaid coverage, some may be concerned about the suitability of SSI children as a control group. One response would be that we are comparing the difference between 2005 SSI placebo high- and low-impact children with the difference between 2005 LIM high- and low-impact children rather than directly comparing LIM and 
SSI children. Another would be that it would have been better for us from a research design perspective if the DRA-enhanced citizenship rules were applied randomly across the Medicaid LIM population, but that was not the case. Thus, we are using the best placebo/control groups we have at our disposal.

\section{Disenrollment Simulation}

In order to compare the magnitude of the highimpact recertification coefficient with the lowimpact recertification coefficient in Table 2, we simulated the number of monthly exits for an initial cohort of 100,000 enrollees over the course of 1 year under the assumptions that:

- their 6-month recertification exit rate is given by either the high-impact $(11.41 \%)$ or lowimpact $(9.52 \%)$ absolute effect from Table 2, depending on the group we are considering

- their 12-month recertification exit rate is given by the "other" recertification absolute effect from Table 2 of $5.36 \%$

- all other months are assigned the baseline exit rate of $4.36 \%$.

Table 4A reports the results of this simulation exercise, with the simulated results for the highimpact group in column 1 and the simulated results for the low-impact group in column 2. By design, both columns look the same for months $1-5$ because both start with an equal number of enrollees and apply the baseline exit rate in each month. In month 6 , we see a larger reduction in enrollment for the high-impact group because we applied the high-impact recertification absolute effect estimate to that group.

After 12 months, 52,513 enrollees are estimated to remain in the high-impact group while 53,635 are estimated to remain in the low-impact group, implying an additional 1,121 exits among the high-impact group. If we apply the CMS estimate of $0.10 \%$ of Medicaid enrollees being noncitizens to our hypothetical cohort of 100,000 enrollees and assume all of the noncitizens lose coverage, then this suggests that 100 of these 1,121 additional exits are generated by noncitizens and the remaining 1,021 are citizens. In other words, for every 1 noncitizen that loses Medicaid coverage, 10 citizens lose coverage.

Table 4B reports the results of a similar simulation performed instead using the hazard estimates generated from our 2004 LIM placebo group. While Table 4A predicts an additional 1,121 exits among the high-impact
TABLE 4

Simulation Results: (A) 2005 Main LIM Sample and (B) 2004 Placebo LIM Sample

\begin{tabular}{|c|c|c|}
\hline A) 2005 Main LIM Sample & $\begin{array}{l}\text { High-Impact } \\
\text { First Recert }\end{array}$ & $\begin{array}{l}\text { Low-Impact } \\
\text { First Recert }\end{array}$ \\
\hline $\begin{array}{l}\text { Start with: } \\
\text { End of month 1: } \\
\text { End of month 2: } \\
\text { End of month 3: } \\
\text { End of month 4: } \\
\text { End of month 5: } \\
\text { End of month 6: } \\
\text { End of month 7: } \\
\text { End of month 8: } \\
\text { End of month 9: } \\
\text { End of month 10: } \\
\text { End of month 11: } \\
\text { End of month 12: } \\
\text { Low-High } \\
\% \text { noncitizen: } \\
\text { Estimated \# noncitizens exiting: } \\
\text { Estimated \# citizens exiting: }\end{array}$ & $\begin{array}{l}100,000 \\
95,429 \\
91,067 \\
86,905 \\
82,932 \\
79,142 \\
70,114 \\
66,909 \\
63,851 \\
60,932 \\
58,147 \\
55,489 \\
52,513 \\
1,121 \\
0.10 \% \\
100 \\
1,021\end{array}$ & $\begin{array}{l}100,000 \\
95,429 \\
91,067 \\
86,905 \\
82,932 \\
79,142 \\
71,611 \\
68,338 \\
65,214 \\
62,233 \\
59,389 \\
56,674 \\
53,635 \\
1.12 \%\end{array}$ \\
\hline B) 2004 Placebo LIM Sample & $\begin{array}{c}\text { High-Impact } \\
\text { First Recert }\end{array}$ & $\begin{array}{l}\text { Low-Impact } \\
\text { First Recert }\end{array}$ \\
\hline $\begin{array}{l}\text { Start with: } \\
\text { End of month 1: } \\
\text { End of month 2: } \\
\text { End of month 3: } \\
\text { End of month 4: } \\
\text { End of month 5: } \\
\text { End of month 6: } \\
\text { End of month 7: } \\
\text { End of month 8: } \\
\text { End of month 9: } \\
\text { End of month 10: } \\
\text { End of month 11: } \\
\text { End of month 12: } \\
\text { Low-High } \\
\% \text { noncitizen: } \\
\text { Estimated \# noncitizens exiting: } \\
\text { Estimated \# citizens exiting: }\end{array}$ & $\begin{array}{l}100,000 \\
95,429 \\
91,067 \\
86,905 \\
82,932 \\
79,142 \\
71,584 \\
68,312 \\
65,189 \\
62,209 \\
59,366 \\
56,652 \\
53,919 \\
327 \\
0.10 \% \\
100 \\
227\end{array}$ & $\begin{array}{l}100,000 \\
95,429 \\
91,067 \\
86,905 \\
82,932 \\
79,142 \\
72,018 \\
68,726 \\
65,585 \\
62,587 \\
59,726 \\
56,996 \\
54,246 \\
0.33 \%\end{array}$ \\
\hline
\end{tabular}

group, Table 4B predicts only 327 additional exits. As mentioned above, one interpretation of these 327 additional exits is that they represent seasonal differences in exit patterns, free from any confounding effects of the DRA. We could combine the results of both simulation exercises to conclude that the DRA resulted in a net reduction of $794(=1,121-327)$ additional enrollees out of a hypothetical cohort of 100,000 enrollees and, under the same assumptions as above, that 100 of these are noncitizens. This would suggest that for every one noncitizen that loses Medicaid coverage, eight citizens lose coverage.

\section{E. Other Specification Checks}

Our hazard model estimates reported in Table 2 are robust to several alternate specifications involving our modeling of the unemployment rate and the baseline hazard. Rather than modeling the unemployment rate as a dummy equaling one in 
TABLE 5

Duration Model for Georgia LIM Medicaid Spells for Children: Different Approaches to Modeling the Baseline Hazard (Initiated between December 2004 and December 2005)

\begin{tabular}{|c|c|c|c|}
\hline & Quadratic in Time & Weibull Baseline & Cox Model \\
\hline high_impact_first_recert & $2.62 * * *$ & $2.76 * * *$ & $2.63 * * *$ \\
\hline abs. effect & $11.41 \%$ & $12.03 \%$ & $11.46 \%$ \\
\hline low_impact_first_recert & $2.18 * * *$ & $2.43 * * *$ & $1.92 * * *$ \\
\hline abs. effect & $9.52 \%$ & $10.60 \%$ & $8.38 \%$ \\
\hline other_recerts & $1.23 * * *$ & $1.30 * * *$ & $1.99 * * *$ \\
\hline abs. effect & $5.36 \%$ & $5.69 \%$ & $8.68 \%$ \\
\hline \# spells & 104,081 & 104,081 & 104,081 \\
\hline \# exits & 83,789 & 83,789 & 83,789 \\
\hline Log-likelihood & $-130,719.02$ & $-129,842.82$ & $-912,131.46$ \\
\hline Average spell length & 18.46 & 18.46 & 18.46 \\
\hline Average exit probability & $4.36 \%$ & $4.36 \%$ & $4.36 \%$ \\
\hline $\begin{array}{l}\text { Test statistic for test of equality of high-impact and } \\
\text { low-impact hazards }\end{array}$ & 152.06 & 12.18 & 447.09 \\
\hline$p$ value & 0.0000 & 0.0005 & 0.0000 \\
\hline
\end{tabular}

$* * *$ Difference statistically significant at the $1 \%$ level.

months with a higher than average rate, one of our specification checks included the monthly unemployment rate itself. This did not lead to large changes in our key parameters of interest. The results of this specification check are available upon request.

In terms of the baseline hazard, we estimated two alternate specifications. First, we used the Weibull distribution rather than our linear and quadratic time trend terms. Second, we estimated a Cox model, which is a popular empirical specification for hazard models although it does not provide a direct estimate of the baseline hazard. As shown in Table 5, both the Weibull and Cox models estimate a larger hazard on the high-impact first recertification indicator than on the low-impact first recertification indicator. In both cases, the difference is statistically significant. Thus, our results are qualitatively similar regardless of the way in which we model the baseline hazard. In terms of magnitude, the Cox model estimate suggests a bigger difference and the Weibull model suggests a smaller difference between high- and low-impact first recertifications than our primary results. We believe that our approach is preferable to the Weibull model because it allows for more flexibility. In addition, we believe that our approach is preferable to the Cox model, because the Cox model does not provide a direct estimate of the baseline hazard.

\section{DISCUSSION}

Our results suggest that children facing a high-impact first recertification were about 2 percentage points more likely to exit Medicaid than those facing a low-impact first recertification. Such a large difference is not observed if we compare Medicaid children whose first recertification occurred in the summer or fall of 2004 with those whose first recertification occurred in the winter or spring of 2004. This gives us confidence our results are not simply reflecting seasonal differences in exit rates. In addition, we do not observe an impact of the DRA among children enrolled in Medicaid via SSI, as those children were already subject to enhanced citizenship verification.

Two additional pieces of evidence suggest that the vast majority of this increase in Medicaid exits is generated by citizens. First, fewer than 30 of the 104,081 spells in our 2005 LIM sample are initiated by Hispanics, a group that within which we would expect to see a larger than average percentage of noncitizens. ${ }^{11} \mathrm{Sec}-$ ond, prereform estimates by CMS itself suggest that there were very few (roughly $0.10 \%$ ) noncitizen Medicaid enrollees prior to DRA implementation (U.S. Government Accountability Office 2007). Taken together, our results suggest that the DRA-enhanced citizenship verification rules led to an increase in Medicaid disenrollment, and thus a reduction in coverage, among citizens.

These findings lend support to the prereform view of Medicaid directors that if all Medicaid applicants were required to provide documentary evidence of U.S. citizenship, then this would delay eligibility determinations, increase

11. This prevented us from doing any stratification by Hispanic race/ethnicity. 
eligibility personnel costs, as well as be burdensome for applicants and current enrollees (U.S. Department of Health and Human Services 2005). Our findings also lend more rigorous support to the descriptive evidence provided in the GAO post-DRA survey of states which suggested that the DRA resulted in enrollment declines for eligible citizens (U.S. Government Accountability Office 2007). In addition, our results are consistent with the descriptive finding of Ross (2007) and Summer (2009) that while the DRA is aimed at undocumented immigrants, predominantly Hispanics, it was more likely to negatively impact other population groups who are citizens and are eligible for and/or participating in public programs.

We view our findings on the impact of the DRA on citizens as complementing the Sommers (2010) finding that the DRA screened out one in four adult noncitizens in Medicaid and one in eight child noncitizens annually. Combining the two sets of results suggests that while the DRA screened out some noncitizens, this came at the cost of increasing the exit rate of citizens. These findings are consistent with the broader literature on public program participation which finds an inverse relationship between administrative burden (which is often increased in order to screen out those noneligible) and program take-up and retention rates among those eligible to participate.

Our work is subject to a number of limitations. First, because the DRA requirements were not randomized over Medicaid beneficiaries, we are forced to rely on a quasiexperimental research design. However, we find that our results are robust to multiple placebo tests. Second, while state administrative Medicaid data are required to implement our research design, it does not allow us to observe children when they are not enrolled. Thus, inclusion in our sample is conditional on Medicaid enrollment. In addition, the use of state administrative Medicaid data limited our analysis to a single state. Finally, while the Medicaid administrative data are extremely detailed, it does not include a variable directly indicating citizenship status. Our results however are strongly suggestive that the additional Medicaid exits caused by the DRA were generated by citizens.

\section{REFERENCES}

Angus, L., and J. DeVoe. "Evidence that the Citizenship Mandate Curtailed Participation in Oregon's Medicaid Family Planning Program." Health Affairs, 29(4), 2010, 690-8.
Bansak, C., and S. Raphael. "The Effects of State Policy Design Features on Take-Up and Crowd-Out Rates for the State Children's Health Insurance Program." Journal of Policy Analysis and Management, 26(1), 2007, 149-75.

Bronchetti, E. T. "Public Insurance Expansions and the Health of Immigrant and Native Children." Journal of Public Economics, 120, 2014, 205-19.

Dague, L. "The Effect of Medicaid Premiums on Enrollment: A Regression Discontinuity Approach.” Journal of Health Economics, 37, 2014, 1-12.

Herndon, J., W. B. Vogel, R. L. Bucciarelli, and E. A. Shenkman. "The Effect of Renewal Policy Changes on SCHIP Disenrollment." Health Services Research, 43(6), 2008, 2086-105.

Kenney, G., R. A. Allison, J. F. Costich, J. Marton, and J. McFeeters. "Effects of Premium Increases on Enrollment in SCHIP: Findings from Three States." Inquiry, 43(4), 2006, 378-92.

Kenney, G., J. Marton, J. Costich, and J. McFeeters. "Assessing the Potential Enrollment and Budgetary Effects of SCHIP Premiums: Findings from Arizona and Kentucky." Health Services Research, 42(6p2), 2007, 2354-72.

Ketsche, P., E. K. Adams, A. Snyder, M. Zhou, K. Minyard, and R. Kellenberg. "Discontinuity of Coverage for Medicaid and S-CHIP Children at a Transitional Birthday." Health Services Research, 42(6p2), 2007a, 2410-23.

Ketsche, P., E. K. Adams, K. Minyard, and R. Kellenberg. "The Stigma of Public Programs: Does Separate SCHIP Program Reduce It?" Journal of Policy Analysis and Management, 26(4), 2007b, 775-90.

Klevin, J. K., and W. Kopczuk. "Transfer Program Complexity and the Take-Up of Social Benefits." American Economic Journal: Economic Policy, 3, 2011, 54-90.

Marton, J. "The Impact of the Introduction of Premiums into a SCHIP Program." Journal of Policy Analysis and Management, 26(2), 2007, 237-55.

Marton, J., and J. Talbert. "CHIP Premiums, Health Status, and the Insurance Coverage of Children." Inquiry, 47(3), 2010, 199-214.

Marton, J., and A. Yelowitz. "Health Insurance Generosity and Conditional Coverage: Evidence from Medicaid Managed Care in Kentucky." Southern Economic Journal, 82(2), 2015, 535-55.

Marton, J., P. Ketsche, and M. Zhou. "SCHIP Premiums, Enrollment, and Expenditures: A Two State, Competing Risk Analysis.” Health Economics, 19(7), 2010, 772-91.

Marton, J., A. Yelowitz, and J. Talbert. "A Tale of Two Cities? The Heterogeneous Impact of Medicaid Managed Care." Journal of Health Economics, 36, 2014, 47-68.

Marton, J., K. Ketsche, A. Snyder, E. K. Adams, and M. Zhou. "Estimating Premium Sensitivity for Public Health Insurance Coverage: Selection but No Death Spiral." Health Services Research, 50(2), 2015, 579-98.

Ross, D. C. "Medicaid Documentation Requirement Disproportionately Harms Non-Hispanics, New State Data Show: Rule Mostly Hurts U.S. Citizen Children, Not Undocumented Immigrants." Washington, DC: Center on Budget and Policy Priorities, 2007.

Sommers, B. D. "Targeting in Medicaid: The Costs and Enrollment Effects of Medicaid's Citizenship Documentation Requirement." Journal of Public Economics, 94, 2010, 174-82.

Summer, L. "Getting and Keeping Coverage: States' Experience with Citizenship Documentation Rules." New York: The Commonwealth Fund, 2009. 
Truffer, C., J. D. Klemm, E. D. Hoffman, and C. J. Wolfe. Actuarial Report on the Financial Outlook for Medicaid. Washington, DC: Office of the Actuary Centers for Medicare \& Medicaid Services, Department of Health \& Human Services, CMS, 2008.

U.S. Department of Health and Human Services, Office of Inspector General. "Self-Declaration of U.S. Citizenship for Medicaid." Washington, DC: OIG, 2005, July. Accessed April 12, 2010. http://oig.hhs.gov/oei/reports/oei-02-02-00190.pdf

U.S. Government Accountability Office. "States Reported that Citizenship Documentation Requirement Resulted in Enrollment Declines for Eligible Citizens and Posed Administrative Burdens." Washington, DC: GAO, 2007, June. Accessed April 12, 2010. http://www.gao.gov/cgi-bin/getrpt?GAO-07-889

Watson, T. "Inside the Refrigerator: Immigration Enforcement and Chilling Effects in Medicaid Participation." American Economic Journal: Economic Policy, 6(3), 2014, 313-38.

Wolfe, B., and S. Scrivner. "The Devil May Be in the Details: How the Characteristics of SCHIP Programs Affect Take-Up." Journal of Policy Analysis and Management, 24(3), 2005, 499-522. 